\section{La clase de Religión en los colegios públicos de Bogotá: estado de la investigación*}

\author{
William Mauricio Beltrán ${ }^{a}$ \\ Universidad Nacional de Colombia \\ https://orcid.org/0001-7075-3081
}

RECIBIDO: 16-05-19. APROBADO: 05-06-19

Resumen: El artículo presenta la revisión del estado de la investigación sobre las características de la clase de Religión (o educación religiosa escolar, ERE) en los establecimientos educativos del Estado en la ciudad de Bogotá. Así se intenta establecer en qué medida la clase de Religión acata la regulación legal vigente, respeta el principio de laicidad del Estado colombiano y responde a las necesidades de una sociedad en proceso de pluralización religiosa. Se concluye que las normas vigentes son contradictorias y en la práctica incumplibles. En la mayoría de casos, la educación religiosa escolar es confesional católica, lo que acarrea situaciones de discriminación religiosa; y un alto porcentaje de los profesores encargados de esta área no cuentan con la formación adecuada ni con las certificaciones que exige la ley.

Palabras Clave: Educación religiosa escolar, ERE; Bogotá; laicidad; pluralización religiosa; educación básica; educación pública; tolerancia religiosa.

\section{Religious Education Classes in Bogotás Public Schools: Current State of the Research}

AвSTRACT: This article presents a review of the state of the research about the characteristics of Religious Education classes (Educación Religiosa Escolar, or ERE in Spanish) in state-run schools in the city of Bogotá. Through this review, we try to establish the extent to which Religious Education classes comply with the relevant legal regulations, respect the Colombian State's principles of laicism, and meet the needs of a society going through a religious pluralisation process. We conclude that current regulations are contradictory and, in practice, impossible to comply with. In most cases, Religious Education is Catholic in character, which can lead to instances of religious discrimination. A high percentage of the teachers who give these classes do not have the requisite training or certifications as specified by the law.

KEY Words: School Religious Education; Bogotá; Laicism; Religious Pluralization; Basic education; Public education; Religious tolerance

\section{Cómo CITAR:}

Beltrán, William M. "La clase de Religión en los colegios públicos de Bogotá: estado de la investigación". Theologica Xaveriana (2020): 1-29. https://doi.org/10.11144/ javeriana.tx $70 . \operatorname{crcpb}$

\title{
ReCONOCIMIENTO
}

La presente investigación fue financiada por la Universidad Nacional de Colombia. El proyecto se denominó "Educación religiosa y pluralismo en los colegios públicos de Bogotá", y fue desarrollado entre el segundo semestre de 2017 y el segundo semestre de 2018.

*Artículo de investigación

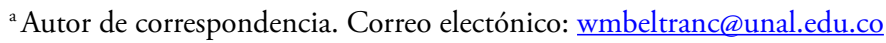




\section{Introducción}

Según el marco legal colombiano, particularmente la Constitución Política de 1991, la Ley General de Educación y la Ley Estatutaria de Libertad Religiosa ${ }^{1}$, aunque el Estado colombiano es aconfesional o laico, en los planes de educación básica y media se mantiene el área de Religión como obligatoria.

Desde la promulgación de la Ley general de educación, una cuantiosa producción bibliográfica se ha ocupado por ofrecer propuestas acerca de cómo se debe concebir esta área en términos de sus contenidos y pedagogías. La mayoría de tales textos ha sido elaborada por filósofos y teólogos católicos que si bien mantienen una perspectiva crítica sobre la normatividad vigente, en términos generales no intentan evaluar lo que está sucediendo en las aulas mediante un acercamiento empírico².

A diferencia de estas investigaciones, se pretende aquí, por medio de la revisión del estado de la investigación, describir qué pasa en las aulas de los establecimientos educativos del Estado en lo referente a la práctica concreta de la clase de Religión; y con base en esta revisión establecer en qué medida, en dicha clase, se acata la normatividad vigente y se acogen los principios constitucionales de multiculturalidad y laicidad.

Entre las preguntas que orientaron la investigación se destacan las siguientes: ¿Cuál es el marco legal que regula la enseñanza de la Religión en los establecimientos educativos del Estado colombiano? ¿Cuáles son las características y los contenidos de la clase de Religión en estos establecimientos? ¿Tiene esta clase un carácter confesional o aconfesional (o laico)? ¿Cuál es el perfil profesional de los docentes que se ocupan de esta área?

\footnotetext{
${ }^{1}$ República de Colombia, "Ley 115 de 1994. Por la cual se expide la Ley General de Educación”; República de Colombia, "Ley 133 de 1994. Por la cual se desarrolla el derecho de libertad religiosa y de cultos".

${ }^{2}$ Ver, por ejemplo, a Coy Africano, “Educación religiosa escolar ¿Por qué y para qué?” 49-70; Guzmán y Arias "La educación religiosa escolarizada”, 33-48; Echeverri Guzmán, “¿Auspiciar o controvertir la libertad religiosa desde la educación? Aportes al debate sobre una educación religiosa pluralista”, 395-416; Meza y Suarez, Educar para la libertad. Una propuesta de educación religiosa escolar en perspectiva liberadora; Corpas de Posada, "Educación religiosa escolar en contextos plurales: lectura teológica del caso colombiano", 77-104; López Altamar, "La educación religiosa escolar en Colombia: su enseńanza en un contexto pluralista y humanizante"; Meza; Suárez; Casas; Garavito; Lara; y Reyes, "Educación religiosa escolar en perspectiva liberadora", 247-262; Bonilla Morales (dir.), Educación religiosa escolar y pedagogías para el reconocimiento del pluralismo religioso; Bonilla Morales, Educación religiosa escolar en perspectiva de complejidad; Bonilla Morales (ed.), Educación y religión: violencia y paz; Bonilla Morales, "Conflicto, religión y educación religiosa en Colombia"; Lara Corredor; Casas; Garavito; Meza; Reyes; y Suárez, "Educación religiosa escolar, una mediación crítica para comprender la realidad", 15-32; Vides San Juan, "La educación religiosa escolar como espacio de formación política. Marco atropopedagógico desde la experiencia de docentes de instituciones educativas distritales de Bogotá"; Valencia Rodríguez, "La educación religiosa escolar como acción educativa, evangelizadora y catequética", 151-193.
} 
Algunas aclaraciones son pertinentes antes de continuar:

1. La revisión cuyos resultados se exponen aquí busca establecer qué está pasando en los establecimientos educativos públicos, que también denominaremos establecimientos educativos del Estado o colegios oficiales. No se incluyen en el análisis los establecimientos educativos de iniciativa privada. Esta decisión obedece a que el marco legal vigente permite que los colegios de iniciativa privada se definan como confesionales, es decir, que enseñen una determinada doctrina religiosa como parte de la formación que consideran adecuada para sus educandos. Por ello se supone que los padres de familia (o tutores) son concientes del carácter confesional o aconfesional de la educación que imparte el colegio en el que matriculan a sus hijos.

Por el contrario -como se precisará adelante-, si bien los establecimientos educativos del Estado están obligados a mantener un área de Educación Religiosa, no deben desarrollar actividades de proselitismo religioso, y los estudiantes pueden solicitar ser eximidos de la clase de religión si así lo desean. Como veremos, esta situación plantea diversos problemas prácticos y se presta para confusiones y malentendidos.

2. La sociedad colombiana experimenta un proceso de pluralización religiosa. Aunque las cifras varían, encuestas recientes muestran que en el país, como en el resto de América Latina, el porcentaje de católicos viene en descenso (actualmente constituye entre el 73 y el $79 \%$ de la población), mientras que crecen otras expresiones religiosas, como los evangélicos y pentecostales (que constituyen entre el 13 y el $14 \%$ ), así como los no afiliados a ninguna confesión religiosa, ateos y agnósticos (que en conjunto suman entre el 6 y el $11 \%$ ). Las demás confesiones religiosas constituyen en conjunto alrededor de $2 \%$ de la población ${ }^{3}$.

Las pocas investigaciones disponibles sobre la pluralización religiosa en la ciudad de Bogotá muestran tendencias similares. Alrededor de $70 \%$ de los bogotanos se identifica como católico, $12 \%$ como evangélico y pentecostal, $4 \%$ de los bogotanos declara no estar afiliado a ninguna confesión religiosa, $7 \%$ se declara ateo o agnóstico, y $6 \%$ de la población manifiesta su adscripción a otras confesiones religiosas, entre ellas los testigos de Jehová y los adventistas 4 . Este nuevo paisaje religioso hace pertinente la pregunta de si los contenidos y dinámicas de la educación religiosa escolar reconocen y reflejan la diversidad religiosa de los bogotanos.

\footnotetext{
${ }^{3}$ Pew Research Center, "Religión en América Latina: cambio generalizado en una región tradicionalmente católica”; Latinobarómetro, "El papa Francisco y la religión en Chile y América Latina”.

${ }^{4}$ Beltrán, "Tendencias cuantitativas del proceso de pluralización religiosa en Bogotá"; Beltrán, "Descripción cuantitativa de la pluralización religiosa en Colombia”.
} 
En nuestra revisión se destacan cuatro investigaciones que, con base en datos empíricos, buscan describir lo que está pasando con la clase de religión en los establecimientos educativos oficiales de la ciudad de Bogotá.

1. Beltrán (2008) expone los resultados de una encuesta realizada a 5.595 estudiantes de grado noveno de 187 instituciones educativas en el Distrito Capital, 86 de ellas de carácter público (el grado noveno es el último grado de formación básica). $52 \%$ de los estudiantes consultados estudiaban en colegios públicos 5 .

2. Castiblanco y Gómez (2008) presentan los resultados de una investigación de campo en nueve colegios de Bogotá6. La muestra incluyó colegios públicos y privados y, entre estos últimos, colegios confesionales y no confesionales. La investigación fue predominantemente cualitativa, basada en observación, etnografía del aula y entrevistas a estudiantes y profesores del área de Religión del grado noveno?.

3. Vides San Juan (2016) ofrece los resultados de una investigación cualitativa basada en entrevistas semiestructuradas a 21 profesores de educación religiosa en el Distrito Capital. La investigación tiene un componente empírico e interpretativo, pero también ofrece una propuesta para hacer de la clase de Religión un espacio de formación política ${ }^{8}$.

4. Hernández, Lozada, Cárdenas, Parra, Silva y Guerrero (2017) indagan sobre lo que está ocurriendo en siete colegios distritales'. A diferencia de las investigaciones anteriores, la de estos autores se enfoca en el grado quinto, y acude a

\footnotetext{
${ }^{5}$ Beltrán, "Actitudes y valoraciones de estudiantes y profesores alrededor de la clase de religión en los colegios de Bogotá", 133-135.

${ }^{6}$ Castiblanco y Gómez, "La clase de religión en Bogotá: un acercamiento cualitativo a las prácticas y dinámicas de la clase”.

${ }^{7}$ Los colegios públicos estudiados fueron: (1) Entre Nubes (localidad San Cristóbal); (2) Antonio Villavicencio (localidad Engativá); (3) Simón Rodríguez (localidad Chapinero); (4) Nuevo Horizonte (localidad Usaquén); 5) INEM Santiago Pérez (localidad Tunjuelito). Colegios privados confesionales: (6) Colegio Americano (presbiteriano, localidad Teusaquillo); (7) Colegio Parroquial San Francisco de Sales (católico, localidad Suba); 8) Gimnasio Los Sauces (localidad Bosa). Colegios privados no confesionales: (9) Instituto Renato Descartes (localidad Kennedy. Ver a Castiblanco y Gómez, "La clase de religión en Bogotá: un acercamiento cualitativo a las prácticas y dinámicas de la clase”, 6-7.

${ }^{8}$ Vides San Juan, "La educación religiosa escolar como espacio de formación política. Marco atropopedagógico desde la experiencia de docentes de Instituciones Educativas Distritales de Bogotá".

${ }^{9}$ Hernández, Lozada, Cárdenas, Parra, Silva y Guerrero, "Educación religiosa y pluralismo en los colegios públicos de Bogotá".
} 
técnicas cualitativas y cuantitativas: observación no participativa, grupos focales, entrevistas y encuestas a estudiantes y profesores ${ }^{10}$.

En adelante se expondrán y compararán los hallazgos de estos estudios y se los analizará en el marco de la normatividad vigente y en relación con otros que se acercan de manera tangencial a los objetivos de la presente investigación o que se realizaron en otras regiones del país.

El análisis se organiza con base en cuatro secciones. En la primera se exponen los aspectos legales vigentes que incumben al área de Religión en la educación pública. En la segunda se ofrece una descripción de las características de la clase de Religión, especialmente de sus contenidos y de las prácticas que son frecuentes. El tercer apartado intenta una caracterización de los docentes, especialmente se ocupa de su formación académica, de sus creencias y de sus credenciales. En la última sección se exponen algunas situaciones de intolerancia religiosa en la escuela pública que están relacionadas con el estado actual de la clase de Religión.

\section{Aspectos legales concernientes a la educación religiosa escolar}

La Constitución política de Colombia "garantiza la libertad de conciencia" y "la libertad de cultos". Precisa que "todas las confesiones religiosas e iglesias son igualmente libres ante la ley" ${ }^{11}$. Para los objetivos de la presente investigación es particularmente significativo su Artículo 68: "Los padres de familia tendrán derecho de escoger el tipo de educación para sus hijos menores. En los establecimientos del Estado ninguna persona podrá ser obligada a recibir educación religiosa" ${ }^{12}$.

Aunque la Constitución no define al Estado colombiano como aconfesional o laico, la Corte Constitucional considera que el carácter laico del Estado colombiano está implícito en la Constitución:

La Constitución de 1991 establece el carácter pluralista del Estado social de derecho colombiano, del cual el pluralismo religioso es uno de los componentes más importantes. Igualmente, la Carta excluye cualquier forma de confesionalismo y consagra la plena libertad religiosa y el tratamiento igualitario de todas

\footnotetext{
${ }^{10}$ Los colegios estudiados fueron: (1) Colegio Garcés Navas y (2) Colegio Distrital Charry (ambos ubicados en la localidad de Engativá); (3) Colegio San Pablo Cedid (localidad de Bosa); (4) Colegio el Jazmín y (5) Colegio Luis Carlos Galán Sarmiento (ambos de la localidad de Puente de Aranda) (6) Colegio Distrital de Kennedy y (7) Colegio San José de Kennedy (localidad de Kennedy) Ver a Castiblanco y Gómez, "La clase de religión en Bogotá: un acercamiento cualitativo a las prácticas y dinámicas de la clase", 6-8.

${ }^{11}$ República de Colombia, "Constitución política de Colombia”, artículos 18 y 19.

${ }^{12}$ Ibíd., Artículo 68.
} 
las confesiones religiosas [...]. Es por consiguiente un Estado laico. Admitir otra interpretación sería incurrir en una contradicción lógica. ${ }^{13}$

Con la vigencia de la Constitución de 1991, la Corte Constitucional cuestionó el Concordato celebrado entre la República de Colombia y la Santa Sede (firmado en 1887 y revisado en 1973) y declaró "inexequibles" algunos de sus artículos, incluido el Artículo XII, que transcribimos a continuación:

En el desarrollo del derecho que tienen las familias católicas de que sus hijos reciban educación religiosa acorde a su fe, los planes educativos, en los niveles de primaria y secundaria, incluirán en los establecimientos oficiales enseñanza y formación religiosa según el magisterio de la Iglesia. ${ }^{14}$

Sobre la decisión de declarar inexequible este artículo la Corte Constitucional precisó:

Ha de advertirse que con la declaratoria de inexequibilidad de esta norma concordataria, esta Corte no está afirmando que los hijos de familias católicas no reciban la educación religiosa que les corresponde como tales. [...] Mas lo que se censura frente al nuevo Estatuto Constitucional es que compulsivamente sea esa la única enseñanza que deba impartirse en los centros educativos del Estado, sin que se dé opción al alumnado de recibir la de su propia fe, o de no recibir ninguna. ${ }^{15}$

A pesar de esto, y como consecuencia de la presión política ejercida por la Iglesia Católica, que está respaldada por la confesión católica de la mayoría de los colombianos, el Concordato se mantuvo vigente después de ser sometido a algunas modificaciones ${ }^{16}$. En la versión revisada del Concordato se incluyó el Artículo XII, ya citado.

La Ley estatutaria de libertad religiosa y de cultos reitera que ningún ciudadano colombiano será "obligado a practicar actos de culto o a recibir asistencia religiosa contraria a sus convicciones personales", y que cada uno es libre "de elegir para sí y los padres para los menores o los incapaces bajo su dependencia, dentro y fuera del ámbito escolar, la educación religiosa y moral según sus propias convicciones" ${ }^{17}$.

\footnotetext{
${ }^{13}$ Corte Constitucional de Colombia, "Sentencia C-350 de 1994".

${ }^{14}$ República de Colombia, "Concordato entre la República de Colombia y la Santa Sede 1973”.

${ }^{15}$ Corte Constitucional de Colombia, "Sentencia C-027 de 1993".

${ }^{16}$ La Iglesia Católica argumentó que el gobierno de Colombia "no puede desconocer el Artículo 27 de la Convención de Viena ni la cláusula Pacta sunt servanda, principio universal sobre el obligatorio cumplimiento de los tratados internacionales (Torres, "El Concordato está vigente: Santa Sede". Ver también a Cifuentes y Figueroa, "La enseñanza religiosa en el sistema escolar colombiano: el predominio confesional".

${ }^{17}$ República de Colombia, "Ley 133 de 1994. Por la cual se desarrolla el derecho de libertad religiosa y de cultos", Artículo 6.
} 
Para este efecto, los establecimientos docentes ofrecerán educación religiosa y moral a los educandos de acuerdo con la enseñanza de la religión a la que pertenecen, sin perjuicio de su derecho de no ser obligados a recibirla. La voluntad de no recibir enseñanza religiosa y moral podrá ser manifestada en el acto de matrícula... ${ }^{18}$

A mediados de los años 90, algunas denominaciones protestantes manifestaron su inconformidad por el trato preferente que el Estado ofrece a la Iglesia Católica, y exigieron la firma de un Convenio que les garantizara algunas de las concesiones que eran exclusivas de la Iglesia Católica. Esto desembocó en la firma del "Convenio de derecho público interno número 1 de 1997 entre el Estado colombiano y algunas entidades religiosas cristianas no católicas", que entró en vigor por medio del Decreto 354 de 1998. Si bien en este Convenio se abordan diversos aspectos, para los objetivos de esta investigación son pertinentes sus disposiciones respecto de la enseñanza de la religión en la escuela. En este sentido, el mencionado Convenio precisa:

Artículo VII. Se garantiza a los alumnos, a sus padres y a los órganos de gobierno escolar establecidos en la Ley General de Educación, el ejercicio del derecho de los primeros a recibir enseñanza religiosa cristiana no católica, acorde a las doctrinas de la entidad religiosa a la que pertenezca, en los centros docentes públicos, en los niveles de educación preescolar a secundaria. Tal garantía no debe representar carácter excluyente con otras religiones.

Artículo XIII. Para ejercer la docencia en el área de Educación Religiosa cristiana no católica, se requiere título de Licenciado en Educación o de Postgrado en Educación con énfasis en estudios de ciencias religiosas cristianas o teología, expedido por una universidad o por una institución de educación superior nacional o extranjera. ${ }^{19}$

Tal y como ha señalado el teólogo Echeverri Guzmán, algunos de los compromisos suscritos por el Estado en este Convenio son poco realistas. Por ejemplo, no es claro cómo va a garantizar una educación religiosa "conforme a los principios y doctrinas de la entidad religiosa cristiana no católica" a la que pertenecen los miembros de trece confesiones religiosas diferentes ${ }^{20}$. Cumplir esta norma implica

\footnotetext{
${ }^{18}$ Ibíd.

${ }^{19}$ República de Colombia-Presidencia, "Decreto 354 de 1998”.

${ }^{20}$ El siguiente es el listado de las entidades religiosas que suscribieron el Convenio de derecho público interno número 1 de 1997: (1) Concilio de las Asambleas de Dios; (2) Iglesia Cruzada Cristiana; (3) Iglesia Cristiana Cuadrangular; (4) Iglesia de Dios en Colombia; (5) Casa sobre la Roca; (6) Iglesia Pentecostal Unida de Colombia; (7) Denominación Misión Panamericana; (8) Iglesia de Dios Pentecostal Movimiento Internacional en Colombia; (9) Iglesia Adventista del Séptimo Día; (10) Iglesia Wesleyana; (11) Iglesia Cristiana de Puente Largo; (12) Federación Consejo Evangélico de Colombia (Cedecol).
} 
que en cada colegio haya profesores que representasen la diversidad de confesiones religiosas con las que el gobierno colombiano ha suscrito convenios o concordatos. Además, no es claro cómo se puede garantizar que este modelo de educación religiosa no acarreará un trato excluyente con aquellas religiones con las que el Estado no ha firmado convenios o concordatos ${ }^{21}$.

Por otro lado, parece conveniente preguntar por qué el profesor de Religión puede acreditarse como idóneo por medio de un diploma en teología. En nuestra opinión, esto confirma que la normatividad vigente concibe el área de Religión en los establecimientos públicos como confesional, ya que tiene como fin garantizar que los estudiantes reciban una formación religiosa que coincida con sus convicciones y, en el caso del menor de edad, con la de sus padres o tutores ${ }^{22}$. La única garantía para que este diseño legal no atente contra los derechos de libertad religiosa y de conciencia es la prescripción constitucional según la cual en "los establecimientos del Estado ninguna persona podrá ser obligada a recibir educación religiosa”23.

Por su parte, la Ley General de Educación define el área de Educación Religiosa como "obligatoria" y "fundamental" para "el logro de los objetivos de la educación básica" 24 , por lo cual los establecimientos educativos deben incluirla "necesariamente" en el currículo y en el proyecto educativo institucional, PEI ${ }^{25}$.

No obstante, el Decreto 1278 de 2002 "por el cual se expide el estatuto de profesionalización docente", "prohíbe” expresamente a "los servidores públicos”, "docentes y directivos docentes" "realizar propaganda o proselitismo político o religioso dentro de los centros educativos o lugares de trabajo" ${ }^{26}$.

El Decreto 4500 de 2006 -que "regula el desarrollo del área de Educación Religiosa en los establecimientos educativos que imparten educación formal en los niveles de educación preescolar, básica y media”- precisa algunas disposiciones más y reitera la prohibición de hacer proselitismo religioso en las aulas:

Artículo 4. Evaluación. [...] al estudiante que opte por no tomar la educación religiosa ofrecida por el establecimiento educativo se le ofrecerá un programa alternativo el cual deberá estar previsto en el PEI con base en el cual se le evaluará.

\footnotetext{
${ }^{21}$ Echeverri, "Libertad religiosa y educación en Colombia: ni intocables ni míticas”, 131.

${ }^{22}$ República de Colombia, "Ley 133 de 1994. Por la cual se desarrolla el derecho de libertad religiosa y de cultos".

${ }^{23}$ República de Colombia, “Constitución política de Colombia”, Artículo 68.

${ }^{24}$ República de Colombia, "Ley 115 de 1994. Por la cual se expide la Ley General de Educación”.

${ }^{25}$ Ibíd., Artículo 23.

${ }^{26}$ República de Colombia-Presidencia, “Decreto 1278 de 2002”, Artículo 42.
} 
Artículo 6. Docentes. [...] Ningún docente estatal podrá usar su cátedra, de manera sistemática u ocasional, para hacer proselitismo religioso o para impartir una educación religiosa en beneficio de un credo específico. ${ }^{27}$

Así, la normatividad vigente configura otro complejo problema práctico, ya que los profesores de Religión deben ofrecer una asignatura confesional, que coincida con las convicciones religiosas de sus estudiantes; pero al mismo tiempo deben abstenerse de hacer proselitismo religioso y evitar que se configuren situaciones de discriminación por causa de las creencias religiosas en el aula. ¿Es posible entonces alguna salida práctica para esta encrucijada legal?

\section{Características de la clase de Religión}

Según Beltrán, 27 \% de los estudiantes de colegios públicos considera que el objetivo de la clase de Religión que reciben es aprender una determinada doctrina religiosa; en otras palabras, cree recibir una formación religiosa confesional. La inmensa mayoría relaciona su clase de Religión con el aprendizaje de la doctrina católica. En el mismo sentido se manifestó $39 \%$ de los profesores del sector público, para quienes el colegio en el que laboran tiene carácter confesional. Además, $83 \%$ de los profesores admitió que en sus colegios no hay "estándares curriculares particulares en la enseñanza de la Religión para estudiantes no católicos" ${ }^{28}$.

Según Rodríguez Vargas y Hernández y otros, esta situación se mantiene en la actualidad $^{29}$. Por eso, los profesores de los colegios públicos optan con frecuencia por usar los lineamientos que ofrece para este fin la Conferencia Episcopal de Colombia ${ }^{30}$. Para Rodríguez Vargas, los "enfoques de los estándares de educación religiosa de la Conferencia Episcopal muestran el obvio marco confesional católico" e "incluyen los enfoques bíblico, cristológico y eclesiológico" ${ }^{31}$, En esta apreciación coinciden Meza y otros teólogos y filósofos católicos, quienes hicieron observaciones de campo en

\footnotetext{
${ }^{27}$ República de Colombia-Presidencia, "Decreto 4500 de 2006”.

${ }^{28}$ Beltrán, "Actitudes y valoraciones de estudiantes y profesores alrededor de la clase de religión en los colegios de Bogotá", 146, 160, 171.

${ }^{29}$ Rodríguez Vargas, Estado de la laicidad en Colombia. Informe 2010-2017, 64; Hernández; Lozada; Cárdenas; Parra; Silva; y Guerrero, "Educación religiosa y pluralismo en los colegios públicos de Bogotá, 17-18.

${ }^{30}$ Conferencia Episcopal de Colombia, Estándares para la educación religiosa escolar (ERE) de la Conferencia Episcopal de Colombia.

${ }^{31}$ Rodríguez Vargas, Estado de la laicidad en Colombia. Informe 2010-2017, 65.
} 
catorce colegios de diferentes regiones del país para establecer qué estaba pasando en la clase de Religión ${ }^{32}$ :

Al revisar las propuestas de las instituciones se puede decir que, en general, los contenidos se enmarcan en el desarrollo personal y el conocimiento de asuntos religiosos: la Sagrada Escritura, el Catecismo, la liturgia católica, la vida sacramental y las devociones religiosas, lo que indica que se trata de una educación religiosa escolar confesional o catequesis escolar. ${ }^{33}$

Según Castiblanco y Gómez, la Conferencia Episcopal de Colombia justifica esta orientación confesional con los argumentos de que el catolicismo constituye un patrimonio cultural de la nación y de que la inmensa mayoría de los colombianos se identifica como católica ${ }^{34}$.

Con frecuencia, y como consecuencia de la ausencia de estándares curriculares oficiales que orienten la clase de religión, sus contenidos son elegidos a discreción por el profesor encargado, quien aprovecha la situación para enseñar a los estudiantes sus propias convicciones religiosas. En este sentido, debe recordarse que los profesores que se ocupan del área son católicos en su gran mayoría ${ }^{35}$. Al respecto, Hernández y sus colegas comentan:

Dentro de las herramientas pedagógicas y los contenidos usados en la mayoría de los colegios analizados, se resalta la Biblia como objeto central y orientador del discurso docente. En ninguno de los ejercicios de observación etnográfica se encontró algún otro libro sagrado perteneciente a una religión diferente de la católica. ${ }^{36}$

${ }^{32}$ El trabajo de campo se realizó en los siguientes colegios: (1) Colegio Cristo Rey; (2) Colegio Departamental Integrado Juan Atalaya; (3) Colegio Mariano Ospina Rodríguez (los anteriores son colegios de Cúcuta, Norte de Santander); (4) Institución Educativa Ciudad de Asís (Puerto Asís, Putumayo); (5) Colegio Técnico Agropecuario y Comercial Eutimio Gutiérrez Manjón (Simití, Bolívar); (6) Institución Educativa del Sur (Ipiales, Nariño); (7) Institución Educativa María Luz (Imués, Nariño);

(8) Institución Educativa Misional Santa Teresita (Tumaco, Narińo); (9) Institución Educativa Nuestra Señora del Pilar (Villagarzón, Putumayo); (10) Institución Educativa Pío XII (Mocoa, Putumayo); (11) Institución Educativa Politécnico Marcelo Miranda (Ipiales, Nariño); (12) Institución Educativa Ricaurte (Ricaurte, Nariño); (13) Institución Educativa San Lorenzo de Yaramal (Ricaurte, Nariño); (14) Colegio Técnico Agropecuario y Comercial Alfredo Nobel (Santa Rosa del Sur, Bolívar) (Meza; Suárez; Casas; Garavito; Lara; y Reyes, “Educación religiosa escolar en perspectiva liberadora”. 260).

${ }^{33}$ Ibíd., 255.

${ }^{34}$ Castiblanco y Gómez, "La clase de religión en Bogotá: un acercamiento cualitativo a las prácticas y dinámicas de la clase”, 39.

35 Beltrán, "Actitudes y valoraciones de estudiantes y profesores alrededor de la clase de religión en los colegios de Bogotá", 165; Hernández; Lozada; Cárdenas; Parra; Silva; y Guerrero, "Educación religiosa y pluralismo en los colegios públicos de Bogotá", 59.

${ }^{36}$ Ibíd., 59. 
Investigaciones en diferentes regiones del país confirman el predominio de una educación religiosa escolar confesional en los colegios públicos, y ratifican que, en la ausencia de directrices por parte del Ministerio de Educación, los docentes suelen acudir a los estándares que para este propósito ofrece la Conferencia Episcopal de Colombia ${ }^{37}$.

Tovar Bernal revisa algunas de las cartillas que se usan para la educación religiosa escolar ${ }^{38}$. Todas ellas se inspiran o siguen las orientaciones de la Conferencia Episcopal de Colombia. Entre los objetivos que persiguen estos textos se destacan el "acercamiento al proyecto de vida propuesto por Jesús" ${ }^{39}$, o la enseñanza del "fundamento trinitario de la moral cristiana"40.

Para Castiblanco y Gómez, un programa de educación religiosa diseñado con base en las orientaciones que ofrece la Conferencia Episcopal, "por respetuosa que aspire a ser respecto de las diversas creencias e increencias, sigue siendo una empresa eclesiástica y, en su último designio, catequética, proselitista, de adoctrinamiento, una empresa de transmisión de creencias..." ${ }^{41}$.

Pese a esto, Beltrán, Castiblanco y Gómez, así como Meza y otros coinciden en señalar que es posible encontrar colegios donde la educación religiosa no gira -o por lo menos no exclusivamente- en torno de la enseńanza de una determinada doctrina religiosa ${ }^{42}$. Por ejemplo, se pueden encontrar cursos donde "se desarrollan temas referentes al pluralismo religioso”, que ofrecen información sobre algunas de

\footnotetext{
${ }^{37}$ Ver, por ejemplo, a Coy Africano, "La educación religiosa escolar en un contexto plural. Reflexiones preliminares"; Riveros, "De-efectos-de: textos escolares de educación religiosa escolar como lugarización de lo nacio-religioso"; Meza; Suárez; Casas; Garavito; Lara; y Reyes, "Educación religiosa escolar en perspectiva liberadora"; Bejarano, Ortiz; y Chamorro, "Educación religiosa escolar en la ciudad de Pasto: antecedentes y tendencias (1994 al 2014)"; Roa Quintero, "Prácticas pedagógicas en contextos de pluralidad religiosa en Colombia”.

${ }^{38}$ Tovar Bernal, "El lugar de la enseñanza religiosa en la escuela pública en Colombia", 29-34. Entre las cartillas que Tovar Bernal revisa se encuentran las siguientes: Comunidad Hermanas Vicentinas, Compromiso moral. Educación religiosa, grado noveno; Comunidad Hermanas Vicentinas, Protagonista de una nueva sociedad. Educación religiosa 11; Tobón y Montoya, Proyecto de vida 5: valor del testimonio; Tobón y Montoya, Jardín católico: educación religiosa.

39 Tobón y Montoya, Jardín católico: educación religiosa, 4, citado por Tovar Bernal, "El lugar de la enseńanza religiosa en la escuela pública en Colombia”, 29.

${ }^{40}$ Comunidad Hermanas Vicentinas, Compromiso moral. Educación religiosa, grado noveno, 29, citado por Tovar Bernal, "El lugar de la enseñanza religiosa en la escuela pública en Colombia”, 31.

${ }^{41}$ Castiblanco y Gómez, "La clase de religión en Bogotá: un acercamiento cualitativo a las prácticas y dinámicas de la clase”, 50, citando a Fierro, El hecho religioso en la educación secundaria. Una educación laica para la tolerancia, 66.

${ }^{42}$ Ibíd., 38; Beltrán, "Actitudes y valoraciones de estudiantes y profesores alrededor de la clase de religión en los colegios de Bogotá", 151; Meza; Suárez; Casas; Garavito; Lara; y Reyes, "Educación religiosa escolar en perspectiva liberadora", 255.
} 
las grandes religiones universales desde una perspectiva que sería más cercana a las ciencias sociales, por ejemplo, la historia, la filosofía o la sociología de las religiones ${ }^{43}$.

Castiblanco y Gómez describen una situación similar. La ambigüedad de la normatividad y la falta de instrucciones por parte del Ministerio de Educación permiten mantener una situación de confusión entre docentes y directivas sobre los contenidos que convienen al área de Religión. Por esto es posible observar "gran variedad de programas, con distintas orientaciones, cada uno muy ligado a la visión personal" del profesor ${ }^{44}$.

A pesar de que la Ley General de Educación las define como áreas diferentes ${ }^{45}$, según Beltrán, en buena parte de los colegios de Bogotá los límites y las diferencias entre las áreas de Ética y de Religión no son claros, y los contenidos de estas clases son con frecuencia intercambiables ${ }^{46}$. Las investigaciones de Vides San Juan y de Castiblanco y Gómez llegan a una conclusión similar ${ }^{47}$ : “...el profesor de la clase de Religión es al mismo tiempo el encargado de la clase de Ética”, y en otros casos, "si bien son profesores distintos, las dos clases hacen parte de la misma área, la de Religión o Pastoral". Esta situación facilita "que los espacios de clase se fusionen y sus contenidos se combinen" 48 .

Con frecuencia, los profesores de estas áreas asumen que el aprendizaje de unas determinadas pautas éticas depende, en buena medida, de la exitosa interiorización de los valores y de la doctrina católica por parte de los estudiantes. La vigencia de esta situación es confirmada por Hernández y sus colegas:

...la cátedra de Religión en los establecimientos educativos distritales, por lo general tiene como objetivo forjar en los estudiantes una ética y una moral desde el aprendizaje de unos valores cristianos, [...se abordan] temas como el respeto,

\footnotetext{
${ }^{43}$ Ibíd., 255.

${ }^{44}$ Castiblanco y Gómez, "La clase de religión en Bogotá: un acercamiento cualitativo a las prácticas y dinámicas de la clase", 38.

45 República de Colombia, "Ley 115 de 1994. Por la cual se expide la Ley General de Educación”, Artículo 23.

${ }^{46}$ Beltrán, "Actitudes y valoraciones de estudiantes y profesores alrededor de la clase de religión en los colegios de Bogotá", 176.

${ }^{47}$ Vides San Juan, "La educación religiosa escolar como espacio de formación política. Marco atropopedagógico desde la experiencia de docentes de instituciones educativas distritales de Bogotá"; Castiblanco y Gómez, "La clase de religión en Bogotá: un acercamiento cualitativo a las prácticas y dinámicas de la clase".

${ }^{48}$ Ibíd., 49.
} 
la tolerancia, el perdón, la honestidad, la devoción, la ayuda desinteresada y el amor al prójimo. ${ }^{49}$

Al parecer, los profesores de Religión asocian su clase con una responsabilidad moral particular: ofrecer "la definición e interpretación 'correcta' de lo religioso" y de lo moral ${ }^{50}$. Esto los lleva a preocuparse, más que los demás docentes, por mantener un comportamiento que pueda jugarse como ejemplar desde el punto de vista de la moral cristiana.

Según Beltrán, dos terceras partes de los estudiantes consultados considera que la asistencia a la clase de Religión es obligatoria e ignora el derecho que les asiste de no participar de ella si consideran que va en contravía de sus convicciones. Por su parte, dos terceras partes de los profesores de colegios públicos consultados manifestó que la asistencia a la clase de Religión es obligatoria para todos los estudiantes ${ }^{51}$.

Tanto Castiblanco y Gómez como Hernández y otros confirman estas tendencias: "...en las entrevistas con los estudiantes vimos que frente a este derecho [de ser eximidos de la clase de religión] hay un desconocimiento generalizado; la clase según lo que nos dijeron los estudiantes era obligatoria, y la asistencia también era calificada"s2.

Beltrán sostiene que, para los profesores y directivos de los colegios públicos, no es práctico informar a los estudiantes y a sus acudientes acerca del carácter opcional de la clase de Religión. Esto les acarrearía diseñar nuevas actividades académicas destinadas a los estudiantes que expresen su voluntad de ser eximidos de la clase. Solo el $10 \%$ de los profesores consultados manifestó que, en sus colegios, se programan actividades alternativas para los estudiantes que no desean participar de la clase de religión ${ }^{53}$.

Dos situaciones agravan la dimensión confesional de la educación religiosa en los colegios públicos del Distrito Capital. En primer lugar, se constata la pervivencia de la celebración de ritos religiosos en algunas de estas instituciones. En segundo lugar, hay evidencia de la presencia en algunos colegios de símbolos religiosos. A continuación, se describen brevemente estas situaciones por

\footnotetext{
${ }^{49}$ Hernández; Lozada; Cárdenas; Parra; Silva; y Guerrero, "Educación religiosa y pluralismo en los colegios públicos de Bogotá", 6.

${ }^{50}$ Castiblanco y Gómez, "La clase de religión en Bogotá: un acercamiento cualitativo a las prácticas y dinámicas de la clase”, 36: citan a McLaren, La escuela como un performance ritual, 189.

${ }^{51}$ Beltrán, "Actitudes y valoraciones de estudiantes y profesores alrededor de la clase de religión en los colegios de Bogotá", 165.

52 Castiblanco y Gómez, "La clase de religión en Bogotá: un acercamiento cualitativo a las prácticas y dinámicas de la clase”, 54.

${ }^{53}$ Beltrán, "Actitudes y valoraciones de estudiantes y profesores alrededor de la clase de religión en los colegios de Bogotá", 149, 166.
} 
considerarlas parte de un currículo oculto (o no explicito) con miras a ofrecer una determinada formación religiosa a los estudiantes. ${ }^{54}$

\section{Ritos religiosos en los colegios públicos}

$13 \%$ de los estudiantes de colegios públicos declaró para el estudio de Beltrán haberse sentido obligado a participar de ritos religiosos que se celebran en sus colegios, y $12 \%$ de los profesores afirmó que se esperaba que los estudiantes participarán en determinados ritos religiosos como parte de sus deberes.

El carácter católico de los ritos que se celebran en los colegios queda confirmado por el hecho de que son especialmente los estudiantes ateos y los no católicos los que con mayor frecuencia se sienten obligados a participar de ellos. Dos terceras partes de los profesores admitió que, si bien en sus colegios se celebran ritos religiosos, la participación de los estudiantes en ellos es opcional. Entre los ritos que se celebran en los colegios públicos sobresalen las eucaristías católicas ${ }^{55}$.

Rodríguez Vargas suministra evidencias fotográficas para corroborar que se siguen celebrando ritos católicos en colegios del Distrito Capital, y ofrece información de estudiantes no católicos que se han sentido presionados a participar en estos $^{56}$. Las investigaciones de Castiblanco y Gómez y de Hernández y sus colegas confirman esta situación:

Rituales como la oración son comunes en las instituciones que visitamos. Los docentes en los grados de primaria dan relevancia a este acto y varios de ellos aseguraron dar inicio a sus clases con una oración y/o plegaria [...]. Empero, un aspecto que evidenciamos es que estas generalmente inician con un Padrenuestro o una Avemaría, plegarias propias de la religión católica. [...] Así mismo, las oraciones no solo se llevan a cabo en las aulas de clase, también se hacen en los momentos de formación, izadas de bandera y cuando algún docente, familiar o conocido fallece..$^{57}$

Casos de estudiantes que son presionados a participar de ritos que no corresponden con sus creencias religiosas han sido divulgados por otras investigaciones, por la prensa o por portales $w e b^{58}$. Rodríguez Vargas destaca el caso de una profesora de

\footnotetext{
${ }^{54}$ Ibíd., 168-170.

55 Ibíd., 147, 148, 169.

${ }^{56}$ Rodríguez Vargas, Estado de la laicidad en Colombia. Informe 2010-2017, 63, 68.

${ }^{57}$ Hernández; Lozada; Cárdenas; Parra; Silva; y Guerrero, "Educación religiosa y pluralismo en los colegios públicos de Bogotá”, 75, 77.

${ }^{58}$ Ver, por ejemplo, a Molina Roldan, “¿La escuela colombiana nos obliga a ser católicos?”; Bejarano, Ortiz y Chamorro, "Educación religiosa escolar en la ciudad de Pasto: antecedentes y tendencias (1994 al 2014)".
} 
un colegio público, en la ciudad de Fusagasugá, que era presionada por las directivas del colegio a participar de eucaristías católicas. La docente interpuso una tutela que fue fallada en su favor por la Corte Constitucional. En el fallo la Corte precisa:

...existe un desconocimiento del principio de laicidad y el deber de neutralidad del Estado en materia religiosa, por parte de la Institución Educativa Municipal Carlos Lozano y Lozano, lo que evidencia que aún persiste una amenaza de vulneración, no solo de los derechos de libertad de cultos y de conciencia de la peticionaria, sino también de los del resto de la comunidad educativa. ${ }^{59}$

\section{Símbolos religiosos como parte del ornato de los colegios públicos}

Sobre la presencia de símbolos religiosos como parte del ornato de los colegios públicos (como pinturas o esculturas de vírgenes, cristos o santos católicos), tanto Castiblanco y Gómez, como Hernández y sus colegas observaron que algunos colegios mantienen este tipo de símbolos en lugares visibles, como el patio central, o incluso en los salones de clase, y los respectivos informes de investigación incluyen registros fotográficos que lo confirman ${ }^{60}$. Por ejemplo, Castiblanco y Gómez relatan lo siguiente sobre uno de los colegios del Distrito Capital:

...dentro de las instalaciones se cuenta con una capilla propia, en la cual se realizan las eucaristías. Este espacio tiene una decoración evidentemente católica: varias imágenes de la Virgen, en las paredes laterales tiene las imágenes de Jesús en el vía crucis y un púlpito que muestra detrás a un Cristo crucificado. ${ }^{61}$

Tanto Castiblanco y Gómez, como Hernández y otros aclaran que, en términos generales, estos símbolos religiosos no generan incomodidad o malestar en la comunidad escolar o, por lo menos, que esta incomodidad no se expresa en público. Y añaden que esto evidencia la naturalización cultural del catolicismo como la religión que goza de mayor legitimidad en la sociedad bogotana ${ }^{62}$. Por otro lado, Hernández

59 Corte Constitucional de Colombia, “Sentencia T-524 de 2017”. Ver también a Rodríguez Vargas, Estado de la laicidad en Colombia. Informe 2010-2017, 72.

${ }^{60}$ Hernández; Lozada; Cárdenas; Parra; Silva; y Guerrero, "Educación religiosa y pluralismo en los colegios públicos de Bogotá", 77; Castiblanco y Gómez, "La clase de religión en Bogotá: un acercamiento cualitativo a las prácticas y dinámicas de la clase”, 59.

${ }^{61}$ Ibíd., 61-62.

${ }^{62}$ Ibíd. 
y sus colegas enfatizan en que en la mayoría de casos ya se han retirado los símbolos religiosos de los lugares más visibles de los colegios públicos ${ }^{63}$.

Para Castiblanco y Gómez, los ritos religiosos y el uso de símbolos religiosos en colegios públicos hacen parte de "un currículo oculto" "que tiene como finalidad socializar a los alumnos dentro del orden dominante presente en la escuela". En este sentido, los ritos y la iconografía religiosa cumplen una "función política" y actúan como un mecanismo de "control social sobre las posiciones divergentes" ${ }^{64}$.

\section{El profesor o la profesora de Religión en la escuela pública}

Vides San Juan ofrece los siguientes datos cuantitativos, compilados en 2015, sobre los docentes encargados del área de religión en los colegios públicos del Distrito:

...de las 361 instituciones educativas distritales, 120 cuentan con al menos un profesor nombrado para el área; esto es, el 33,24\%. Sin embargo, si se tiene en cuenta que, de estas instituciones, 113 tienen doble jornada, la población estudiantil cuyo espacio de Educación Religiosa es orientado por un docente especialista, es mucho menor. De hecho, de los 33.177 docentes, solo 185 están vinculados para el área de Educación Religiosa, esto es, el 0,55 \%; [...] las cifras evidencian un importante déficit en el número de docentes especialistas en Educación Religiosa, en relación con el número de instituciones educativas distritales y el número de estudiantes atendidos por estas instituciones. ${ }^{65}$

Este mismo autor entrevistó a 21 profesores que atienden la clase de Religión en colegios públicos del Distrito Capital; de ellos, solo ocho habían sido vinculados para esta área específica, once para el área de Ciencias Sociales, uno para el área de Ética y Valores, y uno para Filosofía. Según este investigador, "es común” que los profesores nombrados para el área de Ciencias Sociales asuman también las áreas de Educación Religiosa y Ética. "De hecho, en la mayoría de colegios estas horas se distribuyen con el fin de completar la asignación académica" ${ }^{66}$.

Según la encuesta de Beltrán, la formación académica de los profesores que atienden el área de Educación Religiosa se distribuye así: 26 \% tiene un diploma en

${ }^{63}$ Hernández; Lozada; Cárdenas; Parra; Silva; y Guerrero, "Educación religiosa y pluralismo en los colegios públicos de Bogotá, 79, 83.

${ }^{64}$ Castiblanco y Gómez, "La clase de religión en Bogotá: un acercamiento cualitativo a las prácticas y dinámicas de la clase", 61-62, citando a McLaren, La escuela como un performance ritual, 45-46.

${ }^{65}$ Vides San Juan, "La educación religiosa escolar como espacio de formación política. Marco atropopedagógico desde la experiencia de docentes de instituciones educativas distritales de Bogotá", 165.

${ }^{66}$ Ibíd., 172. 
alguna de las Ciencias Sociales, 17 \% de Teología, $14 \%$ de Filosofía, 8 \% de Filosofía y Teología, 5 \% de Psicología, 4 \% de Preescolar, y 3 \% de Pedagogía. Estas serían las áreas dominantes, pero se pueden encontrar docentes de Religión titulados en Comercio, Química, Biología, Contaduría y Educación Física, entre otros ${ }^{67}$. Las investigaciones de Castiblanco y Gómez, y de Hernández y otros, coinciden con esta descripción.

En los diferentes colegios en los que realizamos el trabajo de campo, encontramos una diversidad de perfiles de profesores encargados del área de religión. La mayoría eran licenciados en Ciencias Sociales, y solo algunos habían tomado cursos que certificaban su idoneidad para dictar la clase de religión, dictados por la Arquidiócesis de Bogotá o por universidades confesionales como la Javeriana o la San Buenaventura. En toda la muestra encontramos solo tres profesores certificados como licenciados en ciencias religiosas... ${ }^{68}$

La investigación de Hernández y sus colegas, centrada en el quinto grado de educación básica, consultó la opinión de nueve docentes, de los cuales ocho se identificaron como católicos y una como evangélica. Aunque la mayoría cuenta con diplomas en educación infantil, ninguno pudo acreditar formación especializada en algún área relacionada con la Religión, con excepción de un profesor que fue seminarista y miembro de una comunidad de religiosos católicos ${ }^{69}$.

La misma tendencia se puede observar en investigaciones realizadas en otras regiones de Colombia. En términos generales, la mayoría de los docentes que se ocupa del área se ha formado en otras disciplinas, especialmente en Ciencias Sociales, y no cuenta con credenciales que certifiquen su idoneidad para ocuparse de la clase de Religión ${ }^{70}$.

Rodríguez Vargas concidera que el enfoque y los contenidos de la clase de Religión dependen en buena medida de la formación del profesor y del carácter confesional o aconfesional de la universidad en la se formó:

\footnotetext{
${ }^{67}$ Beltrán, "Actitudes y valoraciones de estudiantes y profesores alrededor de la clase de religión en los colegios de Bogotá", 163-164.

${ }^{68}$ Castiblanco y Gómez, "La clase de religión en Bogotá: un acercamiento cualitativo a las prácticas y dinámicas de la clase”, 34 .

${ }^{69}$ Hernández; Lozada; Cárdenas; Parra; Silva; y Guerrero, "Educación religiosa y pluralismo en los colegios públicos de Bogotá", 49.

${ }^{70}$ Ver, por ejemplo, a Lara Corredor, "La idoneidad del docente de Educación Religiosa Escolar, ERE;" Lara; Casas; Garavito; Meza; Reyes; y Suárez, "Educación religiosa escolar, una mediación crítica para comprender la realidad"; Bejarano, Ortiz, y Chamorro. "Educación religiosa escolar en la ciudad de Pasto"; Palacio y Ramírez, "La educación religiosa y el desarrollo de competencias para la convivencia y la paz en el ambiente escolar".
} 
Sobre la orientación que se da a la asignatura de Religión en las instituciones oficiales es difícil tener datos exactos. El enfoque varía entre instituciones, e incluso entre diferentes docentes de un mismo plantel. En muchos casos, si el docente asignado a la clase de Religión tiene una formación en Ciencias Sociales o Filosofía en una universidad pública, es más probable que la clase no tenga un carácter adoctrinador y se presenten las religiones como opciones diferentes que pueden ser tomadas por los estudiantes. Por el contrario, si el docente de Religión fue formado en Licenciatura en Educación Religiosa, o con formación en Filosofía en una universidad católica, es más probable que la clase favorezca al catolicismo y que pueda ser utilizada como espacio para evangelizar. ${ }^{71}$

El Decreto 4500 de 2006 establece que el profesor o la profesora del área de Religión debe contar con un "certificado de idoneidad" expedido "por la respectiva autoridad eclesiástica" 72 . Esto constituye una nueva evidencia de que estas normas conciben el área de Religión como confesional, es decir, que esta tiene como propósito el adoctrinamiento en determinada creencia religiosa. Así, solo una autoridad de la confesión religiosa que se quiere difundir podría determinar quién es idóneo para enseñar su doctrina.

Además de la Iglesia Católica, esta norma puede tener algún sentido para otras iglesias cristianas históricas (como la Anglicana y Luterana), u organizaciones religiosas institucionalizadas y jerarquizadas en las que es relativamente fácil identificar las autoridades eclesiásticas. Sin embargo, constituye una tarea problemática definir cuál es la autoridad eclesiástica competente en el caso de miles de iglesias y denominaciones que actualmente integran el protestantismo colombiano, o para las diversas comunidades musulmanas, judías, budistas o hinduistas presentes en el país.

El teólogo Lara Corredor considera que esta norma implica una doble discriminación para los docentes de Religión. Por un lado, estos son los únicos entre los docentes de educación básica o media a quienes, además de un diploma profesional, se exige un certificado de idoneidad expedido por una autoridad no académica. Por otro lado, en la práctica, solo se reconocen como autoridades eclesiásticas legítimas a los miembros de las jerarquías católicas, ya que un profesor de Religión que presente un certificado de idoneidad de una autoridad religiosa no católica debe empezar por enfrentar la (nada sencilla) tarea de demostrar que la autoridad que expide la certificación es en verdad una autoridad competente de una confesión religiosa reconocida

\footnotetext{
${ }^{71}$ Rodríguez Vargas, Estado de la laicidad en Colombia. Informe 2010-2017, 64.

${ }^{72}$ República de Colombia-Presidencia, “Decreto 4500 de 2006”, Artículo 6.
} 
por el Estado colombiano ${ }^{73}$. Así, de manera implícita, la legislación ofrece un trato preferente a la Iglesia Católica.

Vides San Juan ofrece un largo listado de programas de Licenciatura en Educación Religiosa algunos con énfasis en Filosofía, Moral, Ética, Teología y Ciencias Religiosas, y constata la existencia de algunas especializaciones en Enseñanza Religiosa Escolar. Todos estos programas son ofrecidos por universidades católicas, entre las que se cuentan la Pontificia Universidad Javeriana (Bogotá), la Universidad de la Salle (Bogotá), la Universidad Minuto de Dios (Bogotá), la Universidad San Buenaventura (Bogotá, Cali, Medellín), la Universidad Santo Tomas (Bogotá), la Fundación Universitaria Católica Lumen Gentium (Cali), la Universidad Católica de Manizales (Manizales), la Pontificia Universidad Bolivariana (Medellín); la Universidad Mariana (Pasto), la Universidad Católica de Pereira (Pereira), la Fundación Universitaria Claretiana (Quibdó), la Universidad Católica de Oriente (Rionegro), la Fundación Universitaria Católica del Norte (Santa Rosa de Osos) ${ }^{74}$.

Es pertinente señalar que en Colombia, hoy, funcionan cuatro universidades confesionales no católicas (bautista, presbiteriana, evangélica y adventista) ${ }^{75}$, pero ninguna de ellas tiene su sede en Bogotá; y si bien todas cuentan con un programa de Teología, solo una, la Corporación Universitaria Adventista, ofrece una Licenciatura en Educación Religiosa ${ }^{76}$. Así, en la práctica, exigir un certificado de idoneidad expedido por una autoridad eclesiástica constituye una norma que favorece sobre todo a la Iglesia Católica.

La investigación de Hernández refleja que, en el caso de la educación primaria, se configura una situación que hace aún más difícil que un profesor cuente con formación especializada para asumir la clase de Religión y acredite un certificado de idoneidad expedido por una autoridad eclesiástica, dado que, por lo general, en los grados de educación básica un mismo docente debe "dictar todas las clases sin excepción”. Así, en ninguno de los colegios estudiados se observó que se exigiese a los

\footnotetext{
${ }^{73}$ Lara Corredor, "La idoneidad del docente de Educación Religiosa Escolar, ERE”, 147-148.

${ }^{74}$ Vides San Juan, "La educación religiosa escolar como espacio de formación política. Marco atropopedagógico desde la experiencia de docentes de instituciones educativas distritales de Bogotá", 291-292.

${ }^{75}$ Las universidades confesionales no católicas presentes en Colombia son las siguientes: (1) Corporación Universitaria Reformada, con sede en Barranquilla (https://www.unireformada.edu.co); (2) Seminario Bíblico de Colombia, con sede en Medellín (http://www.unisbc.edu.co); (3) Unibautista Institución Universitaria, con sede en Cali (http://www.unibautista.edu.co/\#); (4) Corporación Universitaria Adventista, con sede en Medellín (https://www.unac.edu.co).

${ }^{76}$ Corporación Universitaria Adventista, "Licenciatura en Educación Religiosa (2018)”.
} 
docentes un certificado de idoneidad expedido por una autoridad eclesiástica como requisito para asumir esta área ${ }^{77}$.

\section{Intolerancia y discriminación por causas religiosas en el contexto escolar}

Los registros cuantitativos disponibles informan de un porcentaje más bien bajo de casos de intolerancia o discriminación por causa de las creencias religiosas en el contexto escolar ${ }^{78}$. Según Beltrán, solo $7 \%$ de los estudiantes "expresó haberse sentido discriminado en alguna ocasión”79. En la indagación de Hernández y sus colegas este porcentaje es de $6 \%{ }^{80}$. Ambas investigaciones coinciden en señalar que la razón por la cual este porcentaje es bajo tiene que ver con que la mayoría de estudiantes se identifica católica, por lo que no sienten malestar alguno al participar en ritos católicos o aprender la doctrina católica en la clase de Religión. Los estudiantes que manifestaron ser víctimas de intolerancia o discriminación por causa de sus creencias se identificaron con frecuencia con confesiones religiosas diferentes a la católica, o se definieron como ateos o no creyentes ${ }^{81}$.

Castiblanco y Gómez coinciden en que, en términos generales, las relaciones entre los estudiantes se caracterizan por la tolerancia. Ellas consideran que esto se relaciona con el hecho de que la diversidad religiosa en la escuela es más bien una diversidad cristiana ${ }^{82}$. Todas las encuestas consultadas coinciden en señalar que alrededor de $90 \%$ de la población colombiana se identifica con alguna vertiente del

${ }_{77}$ Hernández; Lozada; Cárdenas; Parra; Silva; y Guerrero, "Educación religiosa y pluralismo en los colegios públicos de Bogotá", 50, 51, 55.

${ }^{78} \mathrm{La}$ Corte Constitucional define la discriminación como "un acto arbitrario dirigido a perjudicar a una persona o grupo de personas con base principalmente en estereotipos o perjuicios sociales, por lo general ajenos a la voluntad del individuo, como son el sexo, la raza, el origen nacional o familiar, o por razones irrelevantes para hacerse acreedor de un perjuicio o beneficio como la lengua, la religión o la opinión política o filosófica [...] El acto discriminatorio es la conducta, actitud o trato que pretende -consciente o inconscientemente- anular, dominar o ignorar a una persona o grupo de personas, con frecuencia apelando a preconcepciones o prejuicios sociales o personales, y que trae como resultado la violación de sus derechos fundamentales" (Corte Constitucional de Colombia, "Sentencia T-1090 de 2005").

${ }^{79}$ Beltrán, "Actitudes y valoraciones de estudiantes y profesores alrededor de la clase de religión en los colegios de Bogotá", 158.

${ }^{80}$ Hernández; Lozada; Cárdenas; Parra; Silva; y Guerrero, "Educación religiosa y pluralismo en los colegios públicos de Bogotá”, 48.

${ }^{81}$ Ibíd., 47-48; Beltrán, "Actitudes y valoraciones de estudiantes y profesores alrededor de la clase de religión en los colegios de Bogotá”, 159.

${ }^{82}$ Castiblanco y Gómez, "La clase de religión en Bogotá: un acercamiento cualitativo a las prácticas y dinámicas de la clase”, 56. 
cristianismo, en la que es mayoritario el cristianismo católico y, en segundo lugar, el evangélico pentecostal, situación que no cambia en el contexto escolar ${ }^{83}$.

Pese a sus diferencias, las diversas ramas del cristianismo comparten un conjunto de creencias (que incluyen, por ejemplo, el carácter revelado y sagrado de la Biblia y el carácter divino de Jesucristo) y valores. Las minorías que cuestionan estas creencias y valores son las que sufren con mayor frecuencia situaciones de intolerancia o discriminación. En este sentido, es ilustrativo el siguiente extracto de una entrevista a una estudiante de noveno grado:

...pues personalmente es lógico que yo no me siento bien porque yo no comparto la creencia [... de ellos]. Yo no vivo el mismo mundo que están viviendo mis compañeros $[\ldots]$ hay momentos que yo digo: ¡Dios mío, yo que hago acá! Digamos, en la clase de Religión, en debates, es la palabra de cuarenta personas contra la mía [...] y obvio yo me siento muy incómoda... ${ }^{84}$

Según Castiblanco y Gómez, si bien en la mayoría de los casos los estudiantes se inclinan por "respetar la creencia del otro", tienen más problemas de mantener una actitud respetuosa o tolerante frente a quienes optan por el ateísmo. En general, tanto profesores como estudiantes asumen que esta opción es negativa y perjudicial para el estudiante ${ }^{85}$. Según Hernández y otros, entre los profesores creyentes persisten "prejuicios" que estigmatizan a los estudiantes ateos. Estos se expresan en afirmaciones como las siguientes: "Los que no creen o no tienen religión, no son buenos". O "los que no creen en Dios son satánicos".

Para los creyentes -la gran mayoría de la población colombiana- los ateos representan "una contracultura": "la encarnación de todos los antivalores de la sociedad occidental" ${ }^{6}$. Por eso, algunos profesores consideran que no importa qué religión confiesen los estudiantes, lo importante es "que crean en algo". En este mismo sentido, para algunos profesores "la clase de Religión -católica- es una manera de volver a "encauzar a los estudiantes" por el buen camino ${ }^{87}$.

Castiblanco y Gómez concluyen que tal vez los estudiantes puedan encontrar en la escuela cierta "libertad de credo", pero no "libertad de conciencia", ya que en

\footnotetext{
${ }^{83}$ Beltrán, "Actitudes y valoraciones de estudiantes y profesores alrededor de la clase de religión en los colegios de Bogotá", 139.

${ }^{84}$ Castiblanco y Gómez, "La clase de religión en Bogotá: un acercamiento cualitativo a las prácticas y dinámicas de la clase”, 43.

${ }^{85}$ Ibíd., 57.

${ }^{86}$ Hernández; Lozada; Cárdenas; Parra; Silva; y Guerrero, "Educación religiosa y pluralismo en los colegios públicos de Bogotá”, 84.

${ }^{87}$ Ibíd., 63, 69.
} 
el ambiente escolar la opción de "no creer" carece de toda legitimidad"8. Hernández y sus colegas llegan a una conclusión similar: consideran que se siguen presentando casos de intolerancia hacia estudiantes no católicos en los colegios públicos, y que estos afectan sobre todo a los estudiantes ateos y agnósticos ${ }^{89}$.

Así, tal y como ha sido denunciado por algunos teólogos, en el ambiente escolar, en lugar de promoverse el pluralismo, la tolerancia y el respeto por las creencias del otro, se siguen presentando casos de intolerancia y discriminación por causa de las creencias religiosas, y en ocasiones estos son promovidos por los propios profesores y directivas de los colegios ${ }^{90}$.

\section{A manera de conclusión}

En Colombia, la legislación que regula la orientación y los contenidos de la clase de Religión es contradictoria y en la práctica incumplible. Las normas que exigen mantener un área de Educación Religiosa de carácter confesional y, al mismo tiempo, prohibir que esta se use para el proselitismo religioso son excluyentes entre sí. Por otro lado, en lo relacionado con la enseñanza de la Religión en el sistema público de educación, la legislación ofrece un trato preferente a la Iglesia Católica, lo cual viola el principio de laicidad del Estado.

El carácter contradictorio de las normas y la ausencia de orientaciones por parte del Ministerio de Educación sobre los contenidos y las pedagogías pertinentes facilita que los docentes usen la clase de Religión para difundir sus propias creencias entre los estudiantes.

En términos generales, los padres de familia, estudiantes e inclusos profesores del área de Religión desconocen el derecho constitucional según el cual "ninguna persona podrá ser obligada a recibir educación religiosa" ${ }^{91}$. Por tanto, son casi inexistentes los casos en que estudiantes, padres de familia o tutores emprenden acciones con miras a eximir a un estudiante de la clase de Religión. Por la misma razón, casi ningún colegio ofrece alternativas académicas para los estudiantes que piden ser eximidos de esta clase.

${ }^{88}$ Castiblanco y Gómez, "La clase de religión en Bogotá: un acercamiento cualitativo a las prácticas y dinámicas de la clase", 56-57.

${ }^{89}$ Hernández; Lozada; Cárdenas; Parra; Silva; y Guerrero, "Educación religiosa y pluralismo en los colegios públicos de Bogotá”, 20.

${ }^{90}$ Ver, por ejemplo, A Gamboa Ben-Eleázar, “Conflicto religioso en Colombia: entre el fundamentalismo, el laicismo y la cooperación interreligiosa”, 45-46.

${ }^{91}$ República de Colombia, “Constitución política de Colombia 1991”, Artículo 68. 
Por otro lado, el sistema de educación colombiano no cuenta con el personal que permita garantizar a los estudiantes no católicos una "educación religiosa y moral $[\ldots]$ de acuerdo con la enseñanza de la religión a la que pertenecen” ${ }^{92}$, en la práctica -por sus implicaciones económicas y administrativas- esta norma también parece incumplible.

Tanto por el carácter confesional de la clase de Religión, como por la celebración de ritos católicos en los colegios públicos, se configuran situaciones de intolerancia y discriminación por causa de las creencias religiosas en el escenario escolar. Estas afectan especialmente a los estudiantes no católicos y a los estudiantes ateos, y con frecuencia tienen como protagonistas a profesores y directivos. Esta situación es más preocupante aún si se considera que, en una sociedad multicultural, al sistema educativo le cabe alta responsabilidad en el propósito de cultivar en los ciudadanos valores relacionados con la tolerancia y el respeto por las creencias ajenas.

En opinión del autor de estas líneas, la única salida posible frente a tal situación es apostar por un diseño legal coherente con los principios constitucionales de multiculturalidad y laicidad que, además, tenga en cuenta el carácter pluralista de la sociedad colombiana. Ello implica reabrir (si es que en algún momento se ha cerrado) el debate sobre la pertinencia de un área dedicada a la enseñanza de la Religión en la educación pública. Si, surtido dicho debate, la sociedad colombiana decide mantener la clase de Religión, esta debe tener un carácter aconfesional (o laico), o un carácter pluralista.

Se presentan a continuación algunas ideas acerca de cómo pudieran lograrse estos objetivos, con la única intención de animar el debate. Sin embargo, debe tenerse en cuenta que cada una de estas ideas enfrenta oposición en amplios sectores de la ciudadanía y que, para poder implementarse, tendrían que superarse numerosos problemas legales y prácticos.

En principio, un área de Educación Religiosa laica es posible si se abordan las religiones desde la perspectiva de las Ciencias Sociales, y no desde la Teología de ninguna iglesia o credo en particular ${ }^{93}$. Así, el área de Religión en los colegios del Estado debería consistir en la aproximación a las religiones desde la historia, la sociología, la antropología, y la fenomenología de las religiones; y por tanto debería estar a cargo de docentes formados en estas disciplinas.

Por otro lado, una clase de Religión que tuviese en cuenta el pluralismo religioso sería posible si se abren las puertas de los establecimientos educativos públicos a los

\footnotetext{
${ }^{92}$ República de Colombia, "Ley 133 de 1994. Por la cual se desarrolla el derecho de libertad religiosa y de cultos".

${ }^{93}$ Ver a Tovar Bernal, "El lugar de la enseñanza religiosa en la escuela pública en Colombia”, 36-38.
} 
líderes de las diversas confesiones religiosas reconocidas por el Estado colombiano, para que estos asuman esta área de formación. En tal caso, los estudiantes podrían asistir libremente a las clases donde se enseña la doctrina religiosa de su interés. Por consiguiente, esta área no sería obligatoria para los estudiantes, ni debería ser evaluada. Además, el Estado no tendría que destinar partidas presupuestales para remunerar a los profesores encargados, pues la oferta de una formación religiosa pluralista en los colegios públicos dependería exclusivamente de la iniciativa de las instituciones religiosas interesadas en difundir sus doctrinas y, por tanto, estas mismas instituciones tendrían que asumir los costos económicos asociados.

\section{Referencias}

Bejarano, Jessica; Diego A. Ortiz; y Eyner F. Chamorro. "Educación religiosa escolar en la ciudad de Pasto: antecedentes y tendencias (1994 al 2014)". En Educación y religión: violencia y paz, editado por Jaime Laurence Bonilla Morales, 173-226. Bogotá: Editorial Bonaventuriana, 2015.

Beltrán, William Mauricio. "Actitudes y valoraciones de estudiantes y profesores alrededor de la clase de religión en los colegios de Bogotá". En Hacia una educación religiosa pluralista, coordinado por Abraham Magendzo, 133-177. Santiago de Chile: Universidad Academia de Humanismo Cristiano-Instituto Colombiana para el Estudio de las Religiones, 2008.

. "Descripción cuantitativa de la pluralización religiosa en Colombia." Universitas humanistica 73 (2012): 201-237.

- "Tendencias cuantitativas del proceso de pluralización religiosa en Bogotá." Revista colombiana de sociología 32/2 (2009): 157-184. Disponible en: Universidad Nacional de Colombia, http://dx.doi.org/10.15446/rcs (consultado el $1 .^{\circ}$ de noviembre de 2018).

Bonilla Morales, Jaime Laurence. "Conflicto, religión y educación religiosa en Colombia.” Theologica Xaveriana 181 (2016): 207-237. https://doi. org/10.11144/javeriana.tx66-181.crerc

. Educación religiosa escolar en perspectiva de complejidad. Bogotá: Editorial Bonaventuriana, 2015.

(dir.). Educación religiosa escolar y pedagogías para el reconocimiento del pluralismo religioso. Bogotá: Editorial Bonaventuriana, 2014. 
(ed.). Educación y religión: violencia y paz. Bogotá: Editorial Bonaventuriana, 2015 .

Castiblanco, Liliana, y Laura Gómez. "La clase de religión en Bogotá: un acercamiento cualitativo a las prácticas y dinámicas de la clase.” Monografía para obtener el grado en Sociología, Universidad Nacional de Colombia, Bogotá, 2008.

Cifuentes, María Teresa, y Helwar Figueroa. "La enseñanza religiosa en el sistema escolar colombiano: el predominio confesional". En Hacia una educación religiosa pluralista, coordinado por Abraham Magendzo, 195-132. Santiago de Chile: Universidad Academia de Humanismo Cristiano-Instituto Colombiano para el Estudio de las Religiones, 2008.

Comunidad Hermanas Vicentinas. Compromiso moral. Educación religiosa, grado noveno. Bogotá: Kimpres, 2005.

. Protagonista de una nueva sociedad. Educación religiosa 11. Bogotá: Kimpres, 2005.

Conferencia Episcopal de Colombia. Estándares para la educación religiosa escolar en Colombia (ERE) de la Conferencia Episcopal de Colombia. Bogotá: CEC-Departamento de Educación y Culturas, 2017.

Corpas de Posada, Isabel. "Educación religiosa escolar en contextos plurales: lectura teológica del caso colombiano". Ciencias sociales y religión 14/17 (2012): 77-104. https://doi.org/10.22456/1982-2650.26614

Corporación Universitaria Adventista. "Licenciatura en Educación Religiosa (2018)". UNAC, https://www.unac.edu.co/teologia/index.php/licenciatura-en-religion/ (consultado el 9 de diciembre de 2018).

Corte Constitucional de Colombia. "Sentencia C-027 de 1993". Corte Constitucional, http://www.corteconstitucional.gov.co/relatoria/1993/C-027-93.htm (consultado el 6 mayo de 2018).

. "Sentencia C-350 de 1994". Corte Constitucional, http://www.corteconstitucional.gov.co/relatoria/1994/c-350-94.htm (consultado el 6 mayo de 2018).

. "Sentencia T-1090 de 2005”. Corte Constitucional, http://www.corteconstitucional.gov.co/relatoria/2005/t-1090-05.htm (consultado el 6 mayo de 2018). . "Sentencia T-524 de 2017". Corte Constitucional, http://www.corteconstitucional.gov.co/relatoria/2017/t-524-17.htm (consultado el 6 mayo de 2018). 
Coy Africano, María Elizabeth. "Educación religiosa escolar: ¿por qué y para qué?” Franciscanum LI/152 (2009): 49-70. Disponible en: Redalyc, http://www. redalyc.org/pdf/3435/343529072003.pdf

. "La educación religiosa escolar en un contexto plural. Reflexiones preliminares". Franciscanum 52/14) (2010): 53-83. Universidad de San Buenaventura, http://revistas.usb.edu.co/index.php/Franciscanum/article/view/943

Echeverri Guzmán, Alberto. “¿Auspiciar o controvertir la libertad religiosa desde la educación? Aportes al debate sobre una educación religiosa pluralista”. Theologica Xaveriana 60/170 (2010): 395-416. Disponible en: Pontificia Universidad Javeriana, http://revistas.javeriana.edu.co/index.php/teoxaveriana/article/ view/9370

. "Libertad religiosa y educación en Colombia: ni intocables ni míticas". Revista Cientifica Guillermo de Ockham 10/1 (2012): 123-134. Doi: http://dx.doi. org/10.21500/22563202.2381

Fierro, Alfredo. El hecho religioso en la educación secundaria. Una educación laica para la tolerancia. Barcelona: Ice-Horsori, 1997.

Gamboa Ben-Eleázar, Richard. "Conflicto religioso en Colombia: entre el fundamentalismo, el laicismo y la cooperación interreligiosa". Nova et vetera 20/64 (2011): 43-54. DOI: 10.22431/25005103.168\}

Guzmán, Sandra M., y Yulman F. Arias. "La educación religiosa escolarizada”. Revista académica e institucional de la UCPR 84 (2009): 33-48. Disponible en: Dialnet, https://dialnet.unirioja.es/descarga/articulo/4897679.pdf

Hernández, María F.; Susana Lozada; Laura Cárdenas; Mónica Parra; Néstor Silva; y Natalia Guerrero. "Educación religiosa y pluralismo en los colegios públicos de Bogotá". Monografía para obtener el grado en Sociología, Universidad Nacional de Colombia, 2017.

Lara Corredor, Eduardo. "La idoneidad del docente de educación religiosa escolar, ERE”. Reflexiones teológicas 7 (2011): 145-154. Disponible en: Dialnet, https:// dialnet.unirioja.es/descarga/articulo/3745754.pdf

Lara, Eduardo; Juan A. Casas; Daniel de J. Garavito; José L. Meza; José O. Reyes; y Gabriel A. Suárez. "Educación religiosa escolar, una mediación crítica para comprender la realidad”. Magis 7/15 (2015): 15-32.

Latinobarómetro. "El papa Francisco y la religión en Chile y América Latina. Latinobarómetro 1995-2017”. Cooperativa.cl, https://www.cooperativa.cl/noticias/ 
site/artic/20180112/asocfile/20180112124342/f00006494 religion chile america latina 2017.pdf (consultado el 1. ${ }^{\circ}$ de noviembre de 2018).

López Altamar, Julio C. "La educación religiosa escolar en Colombia: su enseñanza en un contexto pluralista y humanizante". Tesis para obtener el grado de Maestría en Educación, Universidad de Antioquia, Medellín, 2014.

McLaren, Peter. La escuela como un performance ritual. Buenos Aires: Siglo XXI, 2003.

Meza, José L., y Gabriel Suárez. Educar para la libertad. Una propuesta de educación religiosa escolar en perspectiva liberadora. Bogotá: San Pablo, 2013.

Meza, José Luis; Gabriel Suárez; Juan A. Casas; Daniel Garavito; David E. Lara; y José O. Reyes. "Educación religiosa escolar en perspectiva liberadora". Civilizar 15/28 (2015): 247-262. Disponible en: Redalyc, http://www.redalyc.org/ pdf/1002/100241608017.pdf

Molina Roldan, Santiago. “¿La escuela colombiana nos obliga a ser católicos?” Las 2Orillas, 28 de octubre de 2014, https://www.las2orillas.co/la-escuela-colombiana-nos-obliga-ser-catolicos/ (consultado el 13 de noviembre de 2018).

Palacio, Carlos J. y Natacha Ramírez. "La educación religiosa y el desarrollo de competencias para la convivencia y la paz en el ambiente escolar". En Educación y religión: violencia y paz, editado por Jaime Laurence Bonilla Morales, 143-171. Bogotá: Editorial Bonaventuriana, 2015.

Pew Research Center. "Religión en América Latina: cambio generalizado en una región tradicionalmente católica”. Pew Research Center (2014), http://www.pewresearch.org/wp-content/uploads/sites/7/2014/11/ PEW-RESEARCH-CENTER-Religion-in-Latin-America-Overview-SPANISH-TRANSLATION-for-publication-11-13.pdf (consultado el 1 de mayo de 2018).

República de Colombia. "Concordato entre la República de Colombia y la Santa Sede 1973”. Conferencia Episcopal de Colombia, https://www.cec.org.co/sites/ default/files/WEB CEC/Documentos/Documentos-Historicos/1973\%20 Concordato\%201973.pdf (consultado el 13 noviembre de 2018).

. "Constitución política de Colombia 1991". Congreso de la República-Senado, http://www.secretariasenado.gov.co/senado/basedoc/constitucion politica 1991.html (consultado el 8 noviembre de 2018). 
. "Ley 115 de 1994. Por la cual se expide la Ley General de Educación”. Mineducación, https://www.mineducacion.gov.co/1621/articles-85906 archivo pdf. pdf (consultado el 6 mayo de 2018).

. "Ley 133 de 1994. Por la cual se desarrolla el derecho de libertad religiosa y de cultos". Mininterior, https://www.mininterior.gov.co/sites/default/files/14 ley_133_94.pdf (consultado el 6 mayo de 2018).

República de Colombia-Presidencia. “Decreto 354 de 1998”. Función Pública, https:// www.funcionpublica.gov.co/eva/gestornormativo/norma.php?i=3278 (consultado el $1 .^{\circ}$ de diciembre de 2018).

. “Decreto 1278 de 2002." Mineducación, https://www.mineducacion.gov. co/1621/articles-86102_archivo_pdf.pdf (consultado $1 .^{\circ}$ de diciembre de 2018).

. “Decreto 4500 de 2006." Mineducación, https://www.mineducacion.gov. co/1621/articles-115381_archivo_pdf.pdf (consultado 1 de diciembre de 2018).

Riveros, Andrés. "De-efectos-de: textos escolares de educación religiosa escolar como lugarización de lo nacio-religioso". Trabajo de Maestría, Departamento de Lenguajes y Estudios Socioculturales, Universidad de Los Andes, Bogotá, 2013.

Roa Quintero, Luisa F. "Prácticas pedagógicas en contextos de pluralidad religiosa en Colombia”. Pensamiento educativo 53/2 (2016): 1-14. Universidad de San Buenaventura, pensamientoeducativo.uc.cl/index.php/pel/article/ download/814/1762Saavedra

Rodríguez Vargas, Ferney. Estado de la laicidad en Colombia. Informe 2010-2017. Bogotá: Bogotá Atea-Asociación de Ateos de Bogotá-International Humanist Secular Union, 2017.

Tobón, Raúl y Oscar Montoya. Jardin católico: educación religiosa. Bogotá: Educar Editores, 2004.

. Proyecto de vida 5: valor del testimonio. Bogotá: Educar Editores, 2002.

Torres, Edgar. "El Concordato está vigente: Santa Sede." Diario El Tiempo, Bogotá, 9 de junio de 1993, El Tiempo.com, https://www.eltiempo.com/archivo/ documento/MAM-217215 (consultado el 8 noviembre de 2018).

Tovar Bernal, Leonardo. "El lugar de la enseñanza religiosa en la escuela pública en Colombia". Tesis de Maestría en Filosofía, Colegio Mayor de Nuestra Señora del Rosario, Bogotá, 2017. 
Valencia Rodríguez, William A. "La educación religiosa escolar como acción educativa, evangelizadora y catequética”. Kénosis 6/11 (2018): 151-193. Disponible en: Revistas UCO, http://revistas.uco.edu.co/index.php/kenosis/article/view/145

Vides San Juan, David E. "La educación religiosa escolar como espacio de formación política. Marco atropopedagógico desde la experiencia de docentes de instituciones educativas distritales de Bogotâ". Tesis para obtener el título de Doctor en Educación y Sociedad, Universidad de La Salle, Bogotá, 2016. 